\title{
Investigation of the Mechanisms of
}

Neuroprotection Mediated by Lobelia Species via Computational Network Pharmacology and Molecular Modeling

\author{
Qinfang Zheng \\ Hunan University of Traditional Chinese Medicine \\ Liangzi Fang \\ Hunan University of Chinese Medicine \\ Xiaolong Huang \\ Hunan University of Chinese Medicine \\ Ye Wang ( $\square$ hhyzwy@126.com) \\ Hunan University of Medicine https://orcid.org/0000-0001-9175-1878 \\ Shuihan Zhang \\ Hunan University of Chinese Medicine
}

\section{Research}

Keywords: Neuroprotection, Lobelia, Network Pharmacology, Docking, Traditional Chinese Medicine, Alzheimer's disease

Posted Date: August 26th, 2020

DOI: https://doi.org/10.21203/rs.3.rs-61537/v1

License: (c) (i) This work is licensed under a Creative Commons Attribution 4.0 International License.

Read Full License 


\section{Abstract}

\section{Background}

Several species of the medicinally valuable genus Lobelia (Campanulaceae) exhibit neuroprotection. While the neuroprotective mechanisms of some components (e.g. lobeline, lobelanine, and lobelanidine) belonging to the $L$. nicotianaefolia or $L$. inflata are extensively characterized, there remains the need to study and elucidate the mechanism of action of other species and their active components. In this work, we have studied the neuroprotective mechanism of the pharmacokinetically favorable active compounds of 17 Lobelia species.

\section{Methods}

Network pharmacology approach and molecular modeling were employed. We have conducted druglikeness evaluation, oral bioavailability prediction followed by the Gene Ontology (GO) terms and pathways enrichment analysis, protein-protein and protein-compound interaction network construction and analysis, and molecular docking studies. Five neurodegenerative diseases viz. Alzheimer's disease, Parkinson's disease, Huntington's disease, epilepsy, and Amyotrophic lateral sclerosis along with the common neuroprotection mechanism-associated genes were evaluated.

\section{Results}

We revealed the neuroprotective mechanism of the active ingredients of Lobelia species. Our study strongly indicates that 12 unique active ingredients viz. luteolin, kaempferol, acacetin, chryseriol, norlobelanine, lobelanine, 2-[(2R,6S)-6-[(2R)-2-hydroxy-2-phenylethyl]-1-methylpiperidin-2-yl]-1phenylethanone, hydroxygenkwanin, lobelanidine, quercetin, and diosmetin regulates 31 targets within multiple signaling pathways. The nitric oxide synthase, brain (NOS1), androgen receptor (ANDR), sodiumand chloride-dependent GABA transporter 1 (SC6A1), apoptosis regulator Bcl-2 (BCL2), RAC-alpha serine/threonine-protein kinase (AKT1), cellular tumor antigen $\mathrm{p53}$, apoptosis regulator BAX, and tumor necrosis factor (TNFA) were identified as the majorly regulated genes. A majority of these target proteins act via several cancer-related pathways proven to have cross-talks with the pathogenesis of neurodegenerative diseases.

\section{Conclusions}

This study explains how the active ingredients of the Lobelia species exhibit their neuroprotective actions and provide a reference basis to investigate their pharmacological effects in detail.

\section{Background}

Neuronal injury is a pathological hallmark of some of the most commonly-known neurodegenerative diseases. In general, the severity of the neuronal damage determines the consequences such as neuronal degeneration or death (1). The etiology and progression of the common neurodegenerative and neuronal 
disorders such as Alzheimer's disease (AD), Parkinson's disease (PD), Huntington's disease (HD), epilepsy, and Amyotrophic lateral sclerosis (ALS) are some well-known examples of the severe consequences of the neuronal damages. The oxidative stress, excitotoxicity, neuroinflammation, mitochondrial dysfunction, and protein aggregations in the brain have been reported to play the central role in the neuronal damages (2).

Neuroprotective strategies and mechanisms that aim to limit the neuronal loss and/or rescue the neuronal damage progression and/or regenerate the neuronal structural and functional integrity are commonly used in several neurodegenerative diseases. Several investigations are also currently underway to find novel ways to protect the nervous system from injury and damage (3). The concept of intervening the neurotransmission receptors by the agonist or antagonist of the natural neurochemical modulators to exhibit the neuroprotection effects has been long-established (4). For example, caffeine, an A2 receptor antagonist was found to protect dopaminergic neurons against the 1-methyl-4-phenyl-1,2,3,6tetrahydropyridine (MPTP)-induced neuronal toxicity in the experimental model of PD (5). Other neurotransmitters such as serotonin, gamma-aminobutyric acid (GABA), and glutamate are also associated with regulating the inhibition and excitation of motor neurons. For example, drugs like flumazenil interact with the GABAergic system and alter motor behavior (6). Other pharmacological interventions are also known to provide neuroprotection as well as disease-modifying activities.

The neurotransmitter receptors modulation, anti-inflammatory responses, and anti-oxidative stress are well-studied pharmacological intervention approaches to protect the neurons. Due to the complex pathways associated with the pathogenesis of neurodegenerative diseases, the paradigm of multi-targetdirected ligands (MTDLs) has been long warranted and has been well-researched in recent years (7-9). Several novel MTDLs with synthetic optimizations have been published in recent years $(10,11)$. In this respect, the herbal medicine or natural products provide an unprecedented advantage of exerting multiple effects on different biological targets (12-14). For example, Crocus sativus, Nigella sativa, Coriandrum sativum, and Ferula assafoetida, Curcuma longa, to name a few, showed neuroprotective effects by regulating multiple disease-associated targets and signaling pathways (15). Curcumin, the major constituent of Curcuma longa, exerts a neuroprotective role in PD via multiple mechanisms including the restoration of the GSH decreased levels, mediation of the overexpression of $\mathrm{BCl}-2$ (inducible nitric oxide synthase (iNOS) antagonist) (16), reduction of pro-inflammatory cytokines such as IL-1 $\beta$, IL-6, TNF-a, total nitrite generation, and decreased activation of NF-KB $(17,18)$.

Lobelia (Campanulaceae) is a genus of flowering plant natives to the temperate and warmer regions with 450 species currently known. Several Lobelia species were traditionally used for medicinal purposes and several species have been continuously evaluated for their distinct pharmacological activities (19). Lobelia chinensis is reported to have anti-oxidative (20), anti-inflammatory (21), anti-viral (21), anti-cancer $(22,23)$ and anti-diabetic properties (24). Lobelia inflata, also known as Indian tobacco, has a long history of use in the treatment of severe breathing problems including asthma, whooping cough, and bronchitis. Amongst the chemical constituents of the Lobelia species, a majority of the research has been performed on pyridine alkaloids such as lobeline, lobelanine, and lobelanidine (25-27). For example, Li et 
al., (28) reported the dopaminergic neuroprotective effects of lobeline against the MPTP-induced dopaminergic neuron death. The lobeline extracted from the leaf of Lobelia nicotianaefolia was shown to have antiepileptic activity by modulating the GABAergic mechanism (29).

Several other chemical classes such as glycosides, lignans, flavonoids, flavonoid, and amino acids endowed with diverse pharmacological effects were revealed (30-34). In a recent study, Ge et al., (24) studied the anti-diabetic mechanism of the metabolites extracted from Lobelia chinensis using network pharmacology approaches. Their study revealed 5-hydroxymethylfurfural and acacetin as two major active ingredients modulating the insulin resistance signaling pathway and diabetic pathway. Moreover, their study also provided a basis for the further study of the active constituents of the Lobelia chinensis in other diseases and their pharmacological mechanisms.

In this study, we performed network pharmacology and molecular modeling analysis of the active ingredients and corresponding targets of 17 herbs of the genus Lobelia. The aim was to decipher their neuroprotective mechanism of action and provide a rationale for future pharmacological studies. The relationships between the active ingredients and potential targets/pathways were established and presented systematically.

\section{Materials And Methods}

\section{Active Ingredients and Biological Targets}

A total of 17 herbs of the genus Lobelia were studied. A total of 233 known active ingredients were retrieved from the Natural Product Activity and Species Source Database (NPASS) (35). The chemical structures and the corresponding targets were mapped to the ChEMBL database (36). Additionally, TCM systems pharmacology database and analysis platform (TCMSP) (37) was also used for the mapping. Three ADME-related properties including $\mathrm{OB}$ (oral bioavailability) $\geq 30 \%$, drug-likeness $(\mathrm{DL}) \geq 0.18$, and half-life $(\mathrm{HL}) \geq 4$ were used to screen the active constituents. The open-source cheminformatics package RDKit (http://www.rdkit.org) was used to standardize the chemical structures and determine the pharmacokinetic parameters (whenever necessary). After that, 49 distinct chemical ingredients and their

411 corresponding targets were selected. Finally, 12 targets that belonged to the cytochrome 450 families were discarded.

\section{Neuroprotection and Neurodegenerative Disease-Related Gene}

The associated-genes of five neurodegenerative diseases viz. AD, ALS, epilepsy, HD, and PD along with the genes associated with the common neuroprotection mechanism were collected. The gene databases viz. GeneCards (38), The Comparative Toxicogenomics Database (CTD) (39), Human Genome Epidemiology (HuGE) Navigator (40) and The Online Mendelian Inheritance in Man (OMIM) (41) were used. Many custom filtering criteria were applied. For example, only the genes annotated to have $\geq 20$ publications associated with them were retrieved from the HuGE navigator database. Only the genes 
annotated with the "protein-coding" function were retrieved from the GeneCards database. Only the genes annotated with the label " $\mathrm{M}$ " and/or " $\mathrm{T}$ " were retrieved from the CTD database. Finally, the total genes collected from the various databases were filtered using the NCBI Gene database and only the "proteincoding" genes were selected.

\section{Enrichment Analysis of Genus Lobelia Targets}

The overlapping targets of genus Lobelia related to the neuroprotection and neurodegenerative diseases were mapped into Gene Ontology (GO), Kyoto Encyclopedia of Genes and Genomes (KEGGs) and REACTOME Pathway (42). The GO functional annotations were carried for the biological process (BP), molecular function (MF), and cellular components (CC) terms (43).

\section{Compound-Target Network Analysis}

The Cytoscape v3.7.2 $(44,45)$ was used to build and analyze the compound-target network. The ECFP4 fingerprints (46) was used to evaluate the chemical diversity of the compounds.

\section{Pharmacology Network Analysis}

The STRING v11 (47) was used to construct the protein-protein interaction (PPI) networks of the overlapping targets related to the genus Lobelia, common neuroprotection, and neurodegenerative diseases. The analysis and modularization were performed using Cytoscape v3.7.2. The MCODE algorithm (48) was used to determine highly interconnected regions in the PPI network. The degree cutoff, node density cutoff, and node score cutoff were kept to $2,0.1$, and 0.2 , respectively.

\section{Molecular Docking}

The docking studies of the representative compounds and targets were performed with AutoDock 4.2 (49) using the UNIX automation script. The BIOVIA Discovery Studio (San Diego: Dassault Systèmes) was used for pre-processing the chemical structures and biomolecules. The metal ions and/or substrate molecules (if any) were kept in the binding pocket of the targets. The Lamarckian genetic algorithm search was employed for the docking. The key residues of the binding pocket were kept flexible. The center of the binding pockets of the individual targets was selected for the grid placement. A total of 60 runs along with 2.5 million energy evaluation steps were employed. The representative pose selection was done based on the cluster analysis of the docked poses. The PyMOL Molecular Graphics System (Version 1.8.4.0, Schrödinger, LLC) was used for the visualizations and graphics generations.

\section{Results}

\section{Lobelia herbs, Active Ingredients, and Known Targets}

In this study, a total of 17 herbs belonging to the genus Lobelia were selected. The criteria of their inclusion in this study were based on available information related to the metabolites and their biological 
targets. For the herbs are known to have at least one experimentally characterized metabolite and one corresponding target was included. The collected herbs are listed in Supplementary Table S1. Initially, the chemical constituents collected from the NPASS database were mapped to the ChEMBL database and the corresponding bioactivity data were retrieved. A total of 194 compounds were successfully mapped in this manner. Additionally, the chemical constituents and corresponding biological targets of Lobelia chinensis were also retrieved from the TCMSP database. A total of 71 chemical constituents were retrieved from the TCMSP database. The redundant chemical structures between the Lobelia chinensis collected from both databases were merged into one and the final selection was based on the TCMSP database. Finally, a total of 233 molecules were subjected to the ADME-filtering. In this study, we used three $A D M E-f i l t e r i n g ~ c r i t e r i a ; O B \geq 30 \%, D L \geq 0.18$, and $\mathrm{HL} \geq 4$. The aim of this filtering was to select the molecules with good absorption, slow metabolism after oral administration, and suitability for the drugdevelopment. A similar approach has been used in other studies (50). In this work, we did not consider the blood-brain barrier (BBB) permeability as filtering criteria. The reason was that certain natural products (e.g. quercetin) with the theoretical prediction of poor BBB permeability when tested experimentally exhibited satisfactory permeability (51). Following the ADME- filtering, 49 unique chemical compounds associated with 411 corresponding targets were selected. Out of that, 12 targets related to the cytochrome 450 families were discarded from further study. Finally, a total of 153 non-reductant targets were studied.

\section{Neuroprotection and Neurodegenerative Disease-Related Gene}

The candidate genes of the five most common neurodegenerative diseases viz. AD (180 genes), ALS (121 genes), epilepsy (2667 genes), HD (65 genes), and PD (127 genes) along with the genes commonly associated with the neuroprotection (NP, 101 genes) mechanism were collected. A series of gene databases (see Material and Methods) were used. Initially, the genes related to each disease and NP mechanism were compared and analyzed individually with the Lobelia genes (153 genes). For the sake of simplicity, this set of genes which includes individual diseases will be called Set I. The overlapped genes of the Set I are shown in Supplementary Figures S1. In the final selection, all the genes associated with five neurodegenerative diseases mentioned above and those of NP mechanisms were overlapped with the Lobelia genes. For the sake of simplicity, this set of genes will be called Set II. To be noted that all the subsequent studies reported in the main paper were performed on Set II. The reason for the selection of Set II for the detailed analysis was because of the fact that different neurodegenerative diseases including those mentioned in this study broadly share the common pathogenesis and signaling pathways related to neuronal damages and protection. Therefore, the genes of the Set II best represented the neuroprotective mechanism associated with different neurodegenerative diseases. Moreover, the analysis related to Set I was also performed (see Supplementary Information).

A total of 31 overlapping genes in Set II were retrieved and the IUPHAR classification (52) was performed on them. The categorical distribution of the overlapped gene is shown in Fig. 1A. As expected, a majority 
of the genes belonged to the enzyme class (56.3\%) followed by ion transporter (12.5\%), nuclear hormone receptors $(12.5 \%)$, other protein $(12.5 \%)$, and catalytic receptor $(6.3 \%)$.

We have also performed a clustering analysis to determine the chemical diversity of the collected chemical constituents. The 49 unique compounds could be represented into 10 well-defined clusters as shown in Fig. 1B. The representative chemical structure of each cluster is shown in Fig. 1C. The aglycone part of the flavonoid such as diosmetin and 18 other aglycones constituted the most populated cluster (Cluster 1).

\section{Enrichment Analysis of the Candidate Genes}

All the overlapped genes belonging to Set I and Set II were tested for functional enrichment with three GO terms (BP, CC, and MF) and KEGG/REACTOME pathways. The result of the $\mathrm{GO}$ terms and KEGG/REACTOME pathways enrichment of genes in Set I are shown in Supplementary Figures S2-S7. The result of the GO enrichment of the genes in Set II is shown in Fig. 2A. The description is provided in the following section.

The "positive regulation of transcription from RNA polymerase II promoter", "positive regulation of transcription, DNA-templated", "response to drug", and "negative regulation of apoptotic process" were the most significantly enriched terms in the BP. Interestingly, the "response to gamma radiation (GO:0010332)" was also found to be within the top ten most enriched BP terms. The ionizing radiation has been shown to have a debilitating impact on neurodegenerative diseases. Several studies reported that radiation inhibits neurogenesis through different mechanisms such as neuroinflammation, elevate reactive oxygen and nitrogen species, oxidative stress, protein degradation, and mitochondrial dysfunctions, among others (53-56). The major cellular components such as nucleus, cytosol, cytoplasm, mitochondria along with synapse were indicated as the location of the overlapped genes in Set II.

The KEGG/REACTOME pathways analysis of overlapped genes were analyzed with $\mathrm{BH}$-corrected $\mathrm{P}$ values $<0.05$ (Fig. 2B). The enrichment of the overlapped genes was mostly found in the pathways in cancer, hepatitis B, Akt signaling pathway, proteoglycans in cancer, MAPK signaling pathway, HTLV-1 infection, prostate cancer, colorectal cancer, influenza A, thyroid hormone signaling pathway, tuberculosis, Chagas disease, endometrial cancer, Amyotrophic lateral sclerosis, and bladder cancer, among other. Indeed, a number of studies supported the intriguing cross-talks between cancer and neurodegeneration (57-59). The key candidate pathways-targets interaction network is shown in Fig. 2C.

\section{Compound-Target Networks}

The compound-target network was constructed to establish the role of the active ingredients of the genus Lobelia and the overlapped targets found in Set I and Set II. The compound-network diagram diagrams of the overlapped genes in AD, ALS, epilepsy, HD, NP, and PD are shown in Supplementary Figures S8-S13 and for Set II is shown in Fig. 3. 
According to the analysis, 12 unique compounds viz. quercetin (MOL000098), luteolin (MOL000006), kaempferol (MOL000422), acacetin (MOL001689), chryseriol (MOL003044), norlobelanine (MOL012216), lobelanine (MOL012208), 2-[(2R,6S)-6-[(2R)-2-hydroxy-2-phenylethyl]-1-methylpiperidin-2-yl]-1phenylethanone (MOL012209), hydroxygenkwanin (MOL005530), lobelanidine (MOL012207), and diosmetin (MOL002881) were found associated with the 31 target proteins in Set II. Among these compounds, quercetin (degree: 26), luteolin (degree: 10), kaempferol (degree: 7), acacetin (degree: 5), and chryseriol (degree: 4 ) were found to be a high-degree association ( $\geq 4$ proteins). Among the targets, nitric oxide synthase, brain (NOS1, degree: 5), androgen receptor (ANDR, degree: 5), sodium- and chloridedependent GABA transporter 1 (SC6A1, degree: 4), BCL2 (degree: 3), AKT1 (degree: 3), P53 (degree: 3), BAX (degree: 3 ), and TNFA (degree: 3 ) were found to be associated with at least three compounds. The candidate compounds and target relationships are listed in Supplementary Table S2-S8.

Certain species of Lobelia, such as Lobelia inflata and Lobelia cardinalis are extensively characterized and the pharmacological properties of their chemical constituents are well-studied (60). Among them, the pyridine alkaloids lobeline and lobinaline were thoroughly investigated $(27,61-63)$. However, due to the structural complexity of the glycosidic components, the evaluation of their bioactivities has been continuing to prove highly challenging. Thus, our study establishing the relationship between the active ingredients of the Lobelia species to their potential targets should aid a tremendous value in elucidating their mechanism of actions in neuroprotection.

\section{Construction and Analysis of Target Proteins PPI Network}

The PPI network was constructed to understand the interrelation between the neuroprotection associated candidate genes of the genus Lobelia. The constructed PPI network is shown in Fig. 4. The network edges were first created based on the molecular interaction by keeping the interaction score to $\geq 0.400$. A total of 31 nodes and 249 edges were found in the network with an average node degree of 16.1. As expected, AKT1, TP53, MYC, TNF, EGF, EGFR were amongst the central targets in the PPI network. In the next step, the highly interconnected regions in the PPI network were analyzed using the MCODE algorithm. A wellorganized and highly interconnected hub region with 20 nodes were retrieved. The targets ESR1, MYC, IL1B, IFNG, CXCL8, CASP9, IL2, CCL2, EGF, EGFR, FOS, MMP2, HSPB1, AKT1, TP53, BCL2L1, AR, HIF1A, TNF, and CCND1 constituted the cluster. Interestingly, all the targets associated in this cluster had an association score $\geq 0.9$, which in turn suggests the high confidence in their interactions. The topological parameters of the PPI network are shown in Table 1. 
Table 1

The topological parameters of the PPI network.

\begin{tabular}{|c|c|c|c|c|}
\hline Genes & Degree & $\begin{array}{l}\text { Betweenness } \\
\text { Centrality }\end{array}$ & $\begin{array}{l}\text { Average Shortest Path } \\
\text { Length }\end{array}$ & Closeness Centrality \\
\hline BCL2L1 & 24 & 0.02054442 & 1.20689655 & 0.82857143 \\
\hline TP53 & 24 & 0.02054442 & 1.20689655 & 0.82857143 \\
\hline AKT1 & 28 & 0.10602706 & 1.03448276 & 0.96666667 \\
\hline GSK3B & 13 & 0.00616809 & 1.5862069 & 0.63043478 \\
\hline EGFR & 21 & 0.01242899 & 1.31034483 & 0.76315789 \\
\hline EGF & 22 & 0.01542304 & 1.27586207 & 0.78378378 \\
\hline BAX & 9 & 0.00049759 & 1.72413793 & 0.58 \\
\hline CASP9 & 19 & 0.01023331 & 1.37931034 & 0.725 \\
\hline CXCL8 & 19 & 0.00330769 & 1.37931034 & 0.725 \\
\hline IL1B & 19 & 0.02195186 & 1.34482759 & 0.74358974 \\
\hline MYC & 24 & 0.02054442 & 1.20689655 & 0.82857143 \\
\hline BCL2 & 11 & 0.00269961 & 1.65517241 & 0.60416667 \\
\hline ESR1 & 21 & 0.01045047 & 1.31034483 & 0.76315789 \\
\hline CCND1 & 20 & 0.01077983 & 1.34482759 & 0.74358974 \\
\hline TNF & 25 & 0.04919786 & 1.13793103 & 0.87878788 \\
\hline HIF1A & 17 & 0.00428457 & 1.44827586 & 0.69047619 \\
\hline AR & 17 & 0.00730507 & 1.44827586 & 0.69047619 \\
\hline FOS & 23 & 0.05947999 & 1.20689655 & 0.82857143 \\
\hline CCL2 & 17 & 0.00290018 & 1.44827586 & 0.69047619 \\
\hline IL2 & 16 & 0.00504994 & 1.48275862 & 0.6744186 \\
\hline IFNG & 14 & 0.00054133 & 1.55172414 & 0.64444444 \\
\hline SOD1 & 16 & 0.02218413 & 1.44827586 & 0.69047619 \\
\hline CTSD & 11 & 0.0013186 & 1.65517241 & 0.60416667 \\
\hline HSPB1 & 17 & 0.00420332 & 1.44827586 & 0.69047619 \\
\hline PRKCB & 9 & 0.00992863 & 1.68965517 & 0.59183673 \\
\hline Nos1 & 7 & 0.00356263 & 1.75862069 & 0.56862745 \\
\hline
\end{tabular}




\begin{tabular}{|lllll|}
\hline Genes & Degree & $\begin{array}{l}\text { Betweenness } \\
\text { Centrality }\end{array}$ & $\begin{array}{l}\text { Average Shortest Path } \\
\text { Length }\end{array}$ & Closeness Centrality \\
\hline MMP2 & 20 & 0.00586964 & 1.34482759 & 0.74358974 \\
\hline SLC6A3 & 6 & 0.02548675 & 1.79310345 & 0.55769231 \\
\hline MAOB & 2 & 0 & 2.62068966 & 0.38157895 \\
\hline ACHE & 7 & 0.04447572 & 1.75862069 & 0.56862745 \\
\hline
\end{tabular}

\section{Molecular docking}

Molecular docking was carried out to elucidate the binding modes of the 12 active ingredients to the 15 targets (NOS1, BCL2, AR, AKT1, AChE, IL2, EGFR, ER, MAOB, PRKCB, CTSD, MMP2, GSK3B, SOD1, and HIF1A) for which crystal structures were known. Interestingly, most of the Lobelia compounds showed a relatively much higher binding affinity against targets such as MAOB (monoamine oxidase B), PRKCB (protein kinase $\mathrm{C}$ beta type), AR (androgen receptor), AChE (acetylcholinesterase), and ER (estrogen receptor) than the other 10 targets. For example, the pyridine alkaloid lobelanidine interacted with MAOB with a docking score of $-11.12 \mathrm{kcal} / \mathrm{mol}$. (2-[(2R,6S)-6-[(2R)-2-hydroxy-2-phenylethyl]-1-methylpiperidin-2yl]-1-phenylethanone) interacted with AChE with a docking score of -11.911, which should be deemed as a potent binding. The docking score of the best-ranked molecules against the selected targets is shown in Table 2. The molecular interactions and binding mode of the selected molecules are shown in Figs. 5-7. 
Table 2

Docking results of the best-ranked candidate compounds.

\begin{tabular}{|c|c|c|c|}
\hline Protein & $\begin{array}{l}\text { PDB } \\
\text { ID }\end{array}$ & Compound ID & $\begin{array}{l}\text { Docking score } \\
\text { (kcal/mol) }\end{array}$ \\
\hline \multirow[t]{5}{*}{ MAOB } & $\begin{array}{l}2 \mathrm{BK} 3 \\
(119)\end{array}$ & MOL012207 (lobelanidine) & -11.12 \\
\hline & & $\begin{array}{l}\text { MOL012209 (2-[(2R,6S)-6-[(2R)-2-hydroxy-2-phenylethyl]-1- } \\
\text { methylpiperidin-2-yl]-1-phenylethanone) }\end{array}$ & -10.506 \\
\hline & & MOL002881 (diosmetin) & -10.488 \\
\hline & & MOL000098 (quercetin) & -10.164 \\
\hline & & MOL012208 (lobelanine) & -10.006 \\
\hline \multirow[t]{3}{*}{ PRKCB } & $\begin{array}{l}210 \mathrm{E} \\
(120)\end{array}$ & MOL005530 (hydroxygenkwanin) & -8.264 \\
\hline & & MOL000098 (quercetin) & -8.189 \\
\hline & & MOL000006 (luteolin) & -8.141 \\
\hline \multirow[t]{4}{*}{ AR } & $\begin{array}{l}\text { 2PIU } \\
(121)\end{array}$ & MOL000006 (luteolin) & -9.38 \\
\hline & & MOL003044 (chryseriol) & -9.224 \\
\hline & & MOL000098 (quercetin) & -9.101 \\
\hline & & MOL000422 (kaempferol) & -9.012 \\
\hline \multirow[t]{4}{*}{ AChE } & $\begin{array}{l}4 \mathrm{EY7} \\
(122)\end{array}$ & $\begin{array}{l}\text { MOL012209 (2-[(2R,6S)-6-[(2R)-2-hydroxy-2-phenylethyl]-1- } \\
\text { methylpiperidin-2-yl]-1-phenylethanone) }\end{array}$ & -11.911 \\
\hline & & MOL012207 (lobelanidine) & -11.756 \\
\hline & & MOL012216 (norlobelanine) & -10.967 \\
\hline & & MOL001689 (acacetin) & -9.233 \\
\hline \multirow[t]{3}{*}{ ER } & $\begin{array}{l}\text { 5TOA } \\
(123)\end{array}$ & MOL000006 (luteolin) & -9.985 \\
\hline & & MOL000098 (quercetin) & -9.948 \\
\hline & & MOL012207 (lobelanidine) & -9.782 \\
\hline
\end{tabular}

Interestingly, the inhibitory effects of some of the compounds revealed in this study against their targets were reported. For example, quercetin and diosmetin were reported to have MAO inhibitory $\mathrm{IC}_{50}$ values of $90 \mu \mathrm{M}((64)$ and $2.10 \mu \mathrm{M}(65)$, respectively. Both quercetin and luteolin were reported to have inhibitory activity on protein kinase $C(66,67)$. Luteolin, quercetin, and kaempferol were reported to suppress the 
function of the AR receptor in different cancer cells (68-70). Likewise, acacetin as well several acacetin derivatives such as linarin (acacetin-7-0- $\beta$-d-rutinoside), acacetin-7-0-methyl ether Mannich base derivatives and acacetin-7-0- $\beta$-D-galactopyranoside were reported to exhibit AChE inhibition (71-73). Quercetin was reported to stimulate cancer cell proliferation via the estrogen receptor (74).

\section{Discussion}

Neurodegenerative diseases such as Alzheimer's disease, Parkinson's disease, Huntington's disease, epilepsy, and Amyotrophic lateral sclerosis are some of the most pressing burdens on the global healthcare system. The high rate of the mortality and morbidity associated with these diseases, particularly in the elderly population, demands novel therapies. Unfortunately, to date, not much success has been achieved in developing effective therapeutics. However, tremendous progress has been made in unraveling the causative mechanism and pathogenesis of these diseases.

One very critical causative mechanism of the most neurodegenerative diseases is the neuronal damage (1). It is now well-established that acute as well as chronic neuronal damage initiates and helps in the progression of neurodegenerative diseases. Thus newer therapeutic strategies to protect the neurons from the damages are needed to be developed (3). In this direction, the use of multi-component herbal products offers a great alternative. Several herbal medicines or natural products are known to exhibit neuroprotection and provide beneficial effects in the treatment of neurodegenerative diseases (12-14). However, there have been several clinical concerns that hinder a wide-adoption of herbal/natural products in the prevention and therapy of neurodegenerative diseases. The lack of scientific evidence or support for patient safety and their efficacy has been often touted as the main reason. Thus, studying the rationale for the explanation of the molecular mechanism of actions of the pharmacokinetically suitable herbal components are of paramount importance.

In this study, through integrated network pharmacology and molecular modeling approach, we aimed to provide an explanation for the neuroprotective mechanism of the chemical constituents of a medically valuable genus called Lobelia. We studied a total of 17 herbs belonging to this genus and their impact on the five neurodegenerative diseases viz. Alzheimer's disease, Parkinson's disease, Huntington's disease, epilepsy, and Amyotrophic lateral sclerosis. Since the neuronal damages associated with the initiation and progression of these diseases share the common mechanism, the overlapped genes associated with these diseases and those related to the genus Lobelia were studied and presented.

After filtering the compounds with favorable ADME-properties, 49 compounds associated with 153 unique target proteins were selected and studied. The results of the network pharmacology (Fig. 3) indicated that 12 compounds viz. quercetin, luteolin, kaempferol, acacetin, chryseriol, norlobelanine, lobelanine, 2-[(2R,6S)-6-[(2R)-2-hydroxy-2-phenylethyl]-1-methylpiperidin-2-yl]-1-phenylethanone, hydroxygenkwanin, lobelanidine, and diosmetin were majorly associated with 31 unique target proteins related to the neuroprotective mechanism. The major targets among them were found to be nitric oxide 
synthase, brain (NOS1), androgen receptor (ANDR), sodium- and chloride-dependent GABA transporter 1 (SC6A1), apoptosis regulator $\mathrm{Bcl}-2$ (BCL2),

RAC-alpha serine/threonine-protein kinase (AKT1), cellular tumor antigen $p 53$, apoptosis regulator BAX, and tumor necrosis factor (TNFA).

KEGG/REACTOME pathways analysis results showed that the candidate genes involved in enriched pathways were related to the relevant pathways in cancer (Fig. 2). Several studies established the crosstalks between the etiology of cancer and neurodegenerative diseases. For example, the role of the cancerassociated enriched targets in this analysis such as the AKT serine/threonine kinase (AKT1) $(75,76)$, BCL2 associated $X$ apoptosis regulator (BAX) (77), apoptosis regulator (BCL2) (78-80), C-X-C motif chemokine ligand 8 (CXCL8) (81-84), Fos proto-oncogene, AP-1 transcription factor subunit (FOS) (85), androgen receptor (AR) $(86,87)$, caspase 9 (CASP9) (88-90), cyclin D1(CCND1) (91, 92), epidermal growth factor receptor (EGFR) $(93,94)$, epidermal growth factor (EGF) $(93,94)$, glycogen synthase kinase 3 beta (GSK3B) (95-98), hypoxia inducible factor 1 alpha subunit (HIF1A) $(99,100)$, matrix metallopeptidase 2 (MMP2) (101-104), protein kinase $C$ beta (PRKCB) (105-107), and tumor protein p53 (TP53) $(108,108-110)$ in neurodegenerative diseases are well-established. These results suggested that the active ingredients of genus Lobelia included in this study may act by targeting the signaling pathways that are common to cancer. Interestingly, the nitric oxide synthase 1 (NOS1) $(111,112)$, tumor necrosis factor (TNF) (113-115), superoxide dismutase 1 (SOD1) (116-118) associated with ALS pathways have their role also associated with neurodegenerative diseases. The analysis of the PPI network (Fig. 4 and Table 1) further confirmed that the majority of these target proteins have molecular interactions with each other and participate in the signaling cascade. Further, the molecular docking studies (Figs. 5-7) performed on the 15 target proteins provide a rationale for the molecular mechanism of the binding of the compounds.

\section{Conclusions}

Neurodegenerative diseases have complex mechanisms with several intertwined signaling pathways and multiple targets associated with it. Therefore, targeting based on multi-ingredient-multi-target-multipathway is highly desirable. In this work, we provide the neuroprotective mechanisms of the 17 herbs belonging to the genus Lobelia. We establish the relationship between their active ingredients and target proteins and signaling pathways. We further provided theoretical validation of the binding mechanism of the compounds with the target proteins. Although our theoretical findings are consistent with other biological reports, further experimental validation of the pharmacological effects would be highly valuable. Moreover, this study provides adequate background and confidence to do so.

\section{Declarations}

\section{Acknowledgements}


Not applicable.

\section{Funding}

The financial support for the work was provided by the China Hunan Provincial Science \& Technology Department (HHN2017SC10, 2015NK2008) and Innovation Project for Graduate Students of Hunan University of Chinese Medicine (2019CX48).

\section{Contributions}

QZ performed all the experiments and drafted the manuscript. SZ and QZ conceived the idea, designed the experimental plan, and revised the manuscript. LF, XH, and YW helped in the collection and validation of the data, provided the supervision of the results, and assisted in revising the manuscript.

\section{Corresponding authors}

Correspondence to Ye Wang or Shuihan Zhang

\section{Ethics declarations}

\section{Ethics approval and consent to participate}

Not applicable.

\section{Consent for publication}

Not applicable.

\section{Competing interests}

The authors declare that the research was conducted in the absence of any commercial or financial relationships that could be construed as a potential conflict of interest.

\section{Availability of data and materials}

All data generated or analysed during this study are included in this published article and its supplementary information files.

\section{References}

1. Vajda FJE. Neuroprotection and neurodegenerative disease. J Clin Neurosci. 2002 Jan 1;9(1):4-8.

2. Leist M, Nicotera P. Apoptosis, excitotoxicity, and neuropathology. Exp Cell Res. 1998 Mar 15;239(2):183-201.

3. Monteiro MC, Coleman MD, Hill EJ, Prediger RD, Maia CSF. Neuroprotection in Neurodegenerative Disease: From Basic Science to Clinical Applications. Oxid Med Cell Longev. 2017;2017:2949102. 
4. Abg Abd Wahab DY, Gau CH, Zakaria R, Muthu Karuppan MK, A-rahbi BS, Abdullah Z, et al. Review on Cross Talk between Neurotransmitters and Neuroinflammation in Striatum and Cerebellum in the Mediation of Motor Behaviour. Biomed Res Int. 2019 Nov 14;2019:1767203.

5. Xu K, Di Luca DG, Orrú M, Xu Y, Chen J-F, Schwarzschild MA. Neuroprotection by caffeine in the MPTP model of parkinson's disease and its dependence on adenosine A2A receptors. Neuroscience. 2016 May 13;322:129-37.

6. Mograbi KDM, de Castro ACF, de Oliveira JAR, Sales PJB, Covolan L, Del Bel EA, et al. Effects of GABAa receptor antagonists on motor behavior in pharmacological Parkinson's disease model in mice. Physiol Rep. 2017 Mar;5(6).

7. Cavalli A, Bolognesi ML, Minarini A, Rosini M, Tumiatti V, Recanatini M, et al. Multi-target-directed ligands to combat neurodegenerative diseases. J Med Chem. 2008 Feb 14;51(3):347-72.

8. Ambure P, Bhat J, Puzyn T, Roy K. Identifying natural compounds as multi-target-directed ligands against Alzheimer's disease: an in silico approach. J Biomol Struct Dyn. 2019 Mar 24;37(5):1282306.

9. Eslami M, Nezafat N, Negahdaripour M, Ghasemi Y. Computational approach to suggest a new multitarget-directed ligand as a potential medication for Alzheimer's disease. J Biomol Struct Dyn. 2019 Dec 12;37(18):4825-39.

10. Benchekroun M, Maramai S. Multitarget-directed ligands for neurodegenerative diseases: real opportunity or blurry mirage? Future Med Chem. 2019;11(4):261-3.

11. Mishra P, Kumar A, Panda G. Anti-cholinesterase hybrids as multi-target-directed ligands against Alzheimer's disease (1998-2018). Bioorg Med Chem. 2019 Mar 15;27(6):895-930.

12. Chen X, Decker M. Multi-target compounds acting in the central nervous system designed from natural products. Curr Med Chem. 2013;20(13):1673-85.

13. Tzvetkov NT, Atanasov AG. Natural product-based multitargeted ligands for Alzheimer's disease treatment? Future Med Chem. 2018;10(15):1745-8.

14. Patil P, Thakur A, Sharma A, Flora SJS. Natural products and their derivatives as multifunctional ligands against Alzheimer's disease. Drug Dev Res. 2020;81(2):165-83.

15. Khazdair MR, Anaeigoudari A, Hashemzehi M, Mohebbati R. Neuroprotective potency of some spice herbs, a literature review. J Tradit Complement Med. 2019 Apr;9(2):98-105.

16. Chen J, Tang XQ, Zhi JL, Cui Y, Yu HM, Tang EH, et al. Curcumin protects PC12 cells against 1methyl-4-phenylpyridinium ion-induced apoptosis by bcl-2-mitochondria-ROS-iNOS pathway. Apoptosis Int J Program Cell Death. 2006 Jun;11(6):943-53.

17. Yang S, Zhang D, Yang Z, Hu X, Qian S, Liu J, et al. Curcumin protects dopaminergic neuron against LPS induced neurotoxicity in primary rat neuron/glia culture. Neurochem Res. 2008 Oct;33(10):2044-53.

18. Ojha RP, Rastogi M, Devi BP, Agrawal A, Dubey GP. Neuroprotective effect of curcuminoids against inflammation-mediated dopaminergic neurodegeneration in the MPTP model of Parkinson's disease. J Neuroimmune Pharmacol Off J Soc Neurolmmune Pharmacol. 2012 Sep;7(3):609-18. 
19. Yang S, Shen T, Zhao L, Li C, Zhang Y, Lou H, et al. Chemical constituents of Lobelia chinensis. Fitoterapia. 2014 Mar 1;93:168-74.

20. Li K-C, Ho Y-L, Huang G-J, Chang Y-S. Anti-oxidative and anti-inflammatory effects of Lobelia chinensis in vitro and in vivo. Am J Chin Med. 2015;43(2):269-87.

21. Kuo P-C, Hwang T-L, Lin Y-T, Kuo Y-C, Leu Y-L. Chemical constituents from Lobelia chinensis and their anti-virus and anti-inflammatory bioactivities. Arch Pharm Res. 2011 May;34(5):715-22.

22. Han S-R, Lv X-Y, Wang Y-M, Gong H, Zhang C, Tong A-N, et al. A study on the effect of aqueous extract of Lobelia chinensis on colon precancerous lesions in rats. Afr $\mathrm{J}$ Tradit Complement Altern Med AJTCAM. 2013;10(6):422-5.

23. Chen M-W, Chen W-R, Zhang J-M, Long X-Y, Wang Y-T. Lobelia chinensis: chemical constituents and anticancer activity perspective. Chin J Nat Med. 2014 Feb;12(2):103-7.

24. Ge Q, Chen L, Yuan Y, Liu L, Feng F, Lv P, et al. Network Pharmacology-Based Dissection of the Antidiabetic Mechanism of Lobelia chinensis. Front Pharmacol [Internet]. 2020 [cited 2020 Apr 11];11. Available from: https://www.frontiersin.org/articles/10.3389/fphar.2020.00347/full

25. Davison GC, Rosen RC. Lobeline and reduction of cigarette smoking. Psychol Rep. 1972 Oct;31(2):443-56.

26. Subarnas A, Oshima Y, Sidik null, Ohizumi Y. An antidepressant principle of Lobelia inflata L. (Campanulaceae). J Pharm Sci. 1992 Jul;81(7):620-1.

27. Dwoskin LP, Crooks PA. A novel mechanism of action and potential use for lobeline as a treatment for psychostimulant abuse. Biochem Pharmacol. 2002 Jan 15;63(2):89-98.

28. Li C-Y, Zhao L-M, Shi X-W, Zhang J-D. Lobeline shows protective effects against MPTP-induced dopaminergic neuron death and attenuates behavior deficits in animals. Exp Ther Med. 2014 Feb;7(2):375-8.

29. Tamboli AM, Rub RA, Ghosh P, Bodhankar SL. Antiepileptic activity of lobeline isolated from the leaf of Lobelia nicotianaefolia and its effect on brain GABA level in mice. Asian Pac J Trop Biomed. 2012 Jul;2(7):537-42.

30. Subarnas A, Tadano T, Oshima Y, Kisara K, Ohizumi Y. Pharmacological properties of beta-amyrin palmitate, a novel centrally acting compound, isolated from Lobelia inflata leaves. J Pharm Pharmacol. 1993 Jun;45(6):545-50.

31. Wilhelm CJ, Johnson RA, Eshleman AJ, Janowsky A. Lobeline effects on tonic and methamphetamine-induced dopamine release. Biochem Pharmacol. 2008 Mar 15;75(6):1411-5.

32. Chen J-X, Huang S-H, Wang L, Han W-L, Wang Y, Zhang D-M, et al. Two pairs of enantiomeric neolignans from Lobelia chinensis. Nat Prod Commun. 2010 Oct;5(10):1627-30.

33. Wang J, Chen L, Qu L, Li K, Zhao Y, Wang Z, et al. Isolation and bioactive evaluation of flavonoid glycosides from Lobelia chinensis Lour using two-dimensional liquid chromatography combined with label-free cell phenotypic assays. J Chromatogr A. 2019 Sep 13;1601:224-31. 
34. Wang H, Li Y, Huang Y, Zhao C, Cheung H-Y. Chemical Profiling of Lobelia chinensis with HighPerformance Liquid Chromatography/Quadrupole Time-of-Flight Mass Spectrometry (HPLC/Q-TOF MS) Reveals Absence of Lobeline in the Herb. Molecules. 2018 Dec;23(12):3258.

35. Zeng X, Zhang P, He W, Qin C, Chen S, Tao L, et al. NPASS: natural product activity and species source database for natural product research, discovery and tool development. Nucleic Acids Res. 2018 Jan 4;46(D1):D1217-D1222.

36. Gaulton A, Hersey A, Nowotka M, Bento AP, Chambers J, Mendez D, et al. The ChEMBL database in 2017. Nucleic Acids Res. 2017 Jan 4;45(D1):D945-D954.

37. Ru J, Li P, Wang J, Zhou W, Li B, Huang C, et al. TCMSP: a database of systems pharmacology for drug discovery from herbal medicines. J Cheminformatics. 2014 Apr 16;6(1):13.

38. Safran M, Dalah I, Alexander J, Rosen N, Iny Stein T, Shmoish M, et al. GeneCards Version 3: the human gene integrator. Database [Internet]. 2010 Jan 1 [cited 2020 Apr 11];2010. Available from: https://academic.oup.com/database/article/doi/10.1093/database/baq020/407450

39. Davis AP, Grondin CJ, Johnson RJ, Sciaky D, King BL, McMorran R, et al. The Comparative Toxicogenomics Database: update 2017. Nucleic Acids Res. 2017 Jan 4;45(D1):D972-8.

40. Yu W, Gwinn M, Clyne M, Yesupriya A, Khoury MJ. A navigator for human genome epidemiology. Nat Genet. 2008 Feb;40(2):124-5.

41. Amberger JS, Bocchini CA, Schiettecatte F, Scott AF, Hamosh A. OMIM.org: Online Mendelian Inheritance in Man $\left(\mathrm{OMIM}{ }^{\circledR}\right)$, an online catalog of human genes and genetic disorders. Nucleic Acids Res. 2015 Jan;43(Database issue):D789-798.

42. Fabregat A, Sidiropoulos K, Viteri G, Forner O, Marin-Garcia P, Arnau V, et al. Reactome pathway analysis: a high-performance in-memory approach. BMC Bioinformatics. 2017 Mar 2;18(1):142.

43. Hill DP, Smith B, McAndrews-Hill MS, Blake JA. Gene Ontology annotations: what they mean and where they come from. BMC Bioinformatics. 2008 Apr 29;9(5):S2.

44. Shannon P, Markiel A, Ozier O, Baliga NS, Wang JT, Ramage D, et al. Cytoscape: A Software Environment for Integrated Models of Biomolecular Interaction Networks. Genome Res. 2003 Nov 1;13(11):2498-504.

45. Otasek D, Morris JH, Bouças J, Pico AR, Demchak B. Cytoscape Automation: empowering workflowbased network analysis. Genome Biol. 2019 Sep 2;20(1):185.

46. Rogers D, Hahn M. Extended-Connectivity Fingerprints. J Chem Inf Model. 2010 May 24;50(5):74254.

47. Szklarczyk D, Gable AL, Lyon D, Junge A, Wyder S, Huerta-Cepas J, et al. STRING v11: protein-protein association networks with increased coverage, supporting functional discovery in genome-wide experimental datasets. Nucleic Acids Res. 2019 Jan 8;47(D1):D607-D613.

48. Bader GD, Hogue CW. An automated method for finding molecular complexes in large protein interaction networks. BMC Bioinformatics. 2003 Jan 13;4(1):2. 
49. Morris GM, Huey R, Lindstrom W, Sanner MF, Belew RK, Goodsell DS, et al. AutoDock4 and AutoDockTools4: Automated docking with selective receptor flexibility. J Comput Chem. 2009;30(16):2785-91.

50. Zeng Q, Li L, Jin Y, Chen Z, Duan L, Cao M, et al. A Network Pharmacology Approach to Reveal the Underlying Mechanisms of Paeonia lactiflora Pall. On the Treatment of Alzheimer's Disease. Evid Based Complement Alternat Med. 2019 Nov 16;2019:8706589.

51. Youdim KA, Qaiser MZ, Begley DJ, Rice-Evans CA, Abbott NJ. Flavonoid permeability across an in situ model of the blood-brain barrier. Free Radic Biol Med. 2004 Mar 1;36(5):592-604.

52. Harding SD, Sharman JL, Faccenda E, Southan C, Pawson AJ, Ireland S, et al. The IUPHAR/BPS Guide to PHARMACOLOGY in 2018: updates and expansion to encompass the new guide to IMMUNOPHARMACOLOGY. Nucleic Acids Res. 2018 Jan 4;46(D1):D1091-D1106..

53. Belarbi K, Jopson T, Arellano C, Fike JR, Rosi S. CCR2 deficiency prevents neuronal dysfunction and cognitive impairments induced by cranial irradiation. Cancer Res. 2013 Feb 1;73(3):1201-10.

54. Greene-Schloesser D, Moore E, Robbins ME. Molecular pathways: radiation-induced cognitive impairment. Clin Cancer Res Off J Am Assoc Cancer Res. 2013 May 1;19(9):2294-300.

55. Acharya MM, Patel NH, Craver BM, Tran KK, Giedzinski E, Tseng BP, et al. Consequences of low dose ionizing radiation exposure on the hippocampal microenvironment. PloS One. 2015;10(6):e0128316.

56. Sharma NK, Sharma R, Mathur D, Sharad S, Minhas G, Bhatia K, et al. Role of Ionizing Radiation in Neurodegenerative Diseases. Front Aging Neurosci [Internet]. 2018 [cited 2020 May 3];10. Available from: https://www.frontiersin.org/articles/10.3389/fnagi.2018.00134/full

57. Plun-Favreau H, Lewis PA, Hardy J, Martins LM, Wood NW. Cancer and Neurodegeneration: Between the Devil and the Deep Blue Sea. PLOS Genet. 2010 Dec 23;6(12):e1001257.

58. Du L, Pertsemlidis A. Cancer and neurodegenerative disorders: pathogenic convergence through microRNA regulation. J Mol Cell Biol. 2011 Jun 1;3(3):176-80.

59. Houck AL, Seddighi S, Driver JA. At the Crossroads Between Neurodegeneration and Cancer: A Review of Overlapping Biology and Its Implications. Curr Aging Sci. 2018;11(2):77-89.

60. Brown DP, Rogers DT, Pomerleau F, Siripurapu KB, Kulshrestha M, Gerhardt GA, et al. Novel multifunctional pharmacology of lobinaline, the major alkaloid from Lobelia cardinalis. Fitoterapia. 2016 Jun;111:109-23.

61. Dimatelis JJ, Russell VA, Stein DJ, Daniels WM. The effects of lobeline and naltrexone on methamphetamine-induced place preference and striatal dopamine and serotonin levels in adolescent rats with a history of maternal separation. Metab Brain Dis. 2012 Sep 1;27(3):351-61.

62. Roni MA, Rahman S. Lobeline attenuates ethanol abstinence-induced depression-like behavior in mice. Alcohol Fayettev N. 2017;61:63-70.

63. Martin CA, Nuzzo PA, Ranseen JD, Kleven MS, Guenthner G, Williams Y, et al. Lobeline Effects on Cognitive Performance in Adult ADHD. J Atten Disord. 2018;22(14):1361-6. 
64. Han XH, Hong SS, Hwang JS, Lee MK, Hwang BY, Ro JS. Monoamine oxidase inhibitory components from Cayratia japonica. Arch Pharm Res. 2007 Jan;30(1):13-7.

65. Han YN, Noh DB, Han DS. Studies on the monoamine oxidase inhibitors of medicinal plants I. Isolation of MAO-B inhibitors fromChrysanthemum indicum. Arch Pharm Res. 1987 Jun 1;10(2):142.

66. Shi R-X, Ong C-N, Shen H-M. Protein Kinase C Inhibition and X-Linked Inhibitor of Apoptosis Protein Degradation Contribute to the Sensitization Effect of Luteolin on Tumor Necrosis Factor-Related Apoptosis-Inducing Ligand-Induced Apoptosis in Cancer Cells. Cancer Res. 2005 Sep 1;65(17):7815-23.

67. Das J, Ramani R, Suraju MO. Polyphenol compounds and PKC signaling. Biochim Biophys Acta. 2016;1860(10):2107-21.

68. Xing N, Chen Y, Mitchell SH, Young CYF. Quercetin inhibits the expression and function of the androgen receptor in LNCaP prostate cancer cells. Carcinogenesis. 2001 Mar 1;22(3):409-14.

69. Yuan H, Young CYF, Tian Y, Liu Z, Zhang M, Lou H. Suppression of the androgen receptor function by quercetin through protein-protein interactions of Sp1, c-Jun, and the androgen receptor in human prostate cancer cells. Mol Cell Biochem. 2010 Jun;339(1-2):253-62.

70. Mamouni K, Zhang S, Li X, Chen Y, Yang Y, Kim J, et al. A Novel Flavonoid Composition Targets Androgen Receptor Signaling and Inhibits Prostate Cancer Growth in Preclinical Models. Neoplasia. 2018 Aug 1;20(8):789-99.

71. Oinonen PP, Jokela JK, Hatakka Al, Vuorela PM. Linarin, a selective acetylcholinesterase inhibitor from Mentha arvensis. Fitoterapia. 2006 Sep 1;77(6):429-34.

72. Wang $X$, Perumalsamy $H$, Kwon HW, Na Y-E, Ahn Y-J. Effects and possible mechanisms of action of acacetin on the behavior and eye morphology of Drosophila models of Alzheimer's disease. Sci Rep. 2015 Nov 4;5(1):1-21.

73. Liu H-R, Men X, Gao X-H, Liu L-B, Fan H-Q, Xia X-H, et al. Discovery of potent and selective acetylcholinesterase (AChE) inhibitors: acacetin 7-0-methyl ether Mannich base derivatives synthesised from easy access natural product naringin. Nat Prod Res. 2018 Mar;32(6):743-7.

74. van der Woude H, Ter Veld MGR, Jacobs N, van der Saag PT, Murk AJ, Rietjens IMCM. The stimulation of cell proliferation by quercetin is mediated by the estrogen receptor. Mol Nutr Food Res. 2005 Aug;49(8):763-71.

75. Rickle A, Bogdanovic N, Volkman I, Winblad B, Ravid R, Cowburn RF. Akt activity in Alzheimer's disease and other neurodegenerative disorders. Neuroreport. 2004 Apr 29;15(6):955-9.

76. Rai SN, Dilnashin H, Birla H, Singh SS, Zahra W, Rathore AS, et al. The Role of PI3K/Akt and ERK in Neurodegenerative Disorders. Neurotox Res. 2019 Apr;35(3):775-95.

77. Vila M, Jackson-Lewis V, Vukosavic S, Djaldetti R, Liberatore G, Offen D, et al. Bax ablation prevents dopaminergic neurodegeneration in the 1-methyl-4-phenyl-1,2,3,6-tetrahydropyridine mouse model of Parkinson's disease. Proc Natl Acad Sci U S A. 2001 Feb 27;98(5):2837-42.

78. Akhtar RS, Ness JM, Roth KA. Bcl-2 family regulation of neuronal development and neurodegeneration. Biochim Biophys Acta. 2004 Mar 1;1644(2-3):189-203. 
79. Sassone J, Maraschi A, Sassone F, Silani V, Ciammola A. Defining the role of the Bcl-2 family proteins in Huntington's disease. Cell Death Dis. 2013 Aug 15;4:e772.

80. Anilkumar U, Prehn JHM. Anti-apoptotic BCL-2 family proteins in acute neural injury. Front Cell Neurosci [Internet]. 2014 [cited 2020 May 4];8. Available from: https://www.frontiersin.org/articles/10.3389/fncel.2014.00281/full

81. Banisor I, Leist TP, Kalman B. Involvement of beta-chemokines in the development of inflammatory demyelination. J Neuroinflammation. 2005 Feb 24;2(1):7.

82. Villa C, Venturelli E, Fenoglio C, Clerici F, Marcone A, Benussi L, et al. CCL8/MCP-2 association analysis in patients with Alzheimer's disease and frontotemporal lobar degeneration. J Neurol. 2009 Aug;256(8):1379-81.

83. Ramesh G, MacLean AG, Philipp MT. Cytokines and Chemokines at the Crossroads of Neuroinflammation, Neurodegeneration, and Neuropathic Pain. Mediators Inflamm. 2013;2013:480739.

84. Lv H, Li J, Che Y-Q. CXCL8 gene silencing promotes neuroglial cells activation while inhibiting neuroinflammation through the PI3K/Akt/NF-KB-signaling pathway in mice with ischemic stroke. J Cell Physiol. 2019;234(5):7341-55.

85. Raivich G, Bohatschek M, Da Costa C, Iwata O, Galiano M, Hristova M, et al. The AP-1 transcription factor c-Jun is required for efficient axonal regeneration. Neuron. 2004 Jul 8;43(1):57-67.

86. Takeyama K, Ito S, Yamamoto A, Tanimoto H, Furutani T, Kanuka H, et al. Androgen-dependent neurodegeneration by polyglutamine-expanded human androgen receptor in Drosophila. Neuron. 2002 Aug 29;35(5):855-64.

87. Nihei Y, Ito D, Okada Y, Akamatsu W, Yagi T, Yoshizaki T, et al. Enhanced aggregation of androgen receptor in induced pluripotent stem cell-derived neurons from spinal and bulbar muscular atrophy. $J$ Biol Chem. 2013 Mar 22;288(12):8043-52.

88. Itżecka J. Serum caspase-9 levels are increased in patients with amyotrophic lateral sclerosis. Neurol Sci. 2012 Aug;33(4):825-9.

89. Tamayev R, Akpan N, Arancio O, Troy CM, D’Adamio L. Caspase-9 mediates synaptic plasticity and memory deficits of Danish dementia knock-in mice: caspase-9 inhibition provides therapeutic protection. Mol Neurodegener. 2012 Dec 10;7:60.

90. Troy CM, Jean YY. Caspases: therapeutic targets in neurologic disease. Neurotherapeutics. 2015 Jan;12(1):42-8.

91. Koeller HB, Ross ME, Glickstein SB. Cyclin D1 in excitatory neurons of the adult brain enhances kainate-induced neurotoxicity. Neurobiol Dis. 2008 Aug;31(2):230-41.

92. Ciapa B, Granon S. Expression of Cyclin-D1 in Astrocytes Varies During Aging. Front Aging Neurosci. 2018;10:104.

93. Wong RWC, Guillaud L. The role of epidermal growth factor and its receptors in mammalian CNS. Cytokine Growth Factor Rev. 2004 Jun;15(2-3):147-56. 
94. Siddiqui S, Fang M, Ni B, Lu D, Martin B, Maudsley S. Central role of the EGF receptor in neurometabolic aging. Int J Endocrinol. 2012;2012:739428.

95. Kaytor MD, Orr HT. The GSK3 beta signaling cascade and neurodegenerative disease. Curr Opin Neurobiol. 2002 Jun;12(3):275-8.

96. Giese KP. GSK-3: a key player in neurodegeneration and memory. IUBMB Life. 2009 May;61(5):51621.

97. Lei P, Ayton S, Bush Al, Adlard PA. GSK-3 in Neurodegenerative Diseases. Int J Alzheimers Dis. 2011;2011:189246.

98. Duda P, Wiśniewski J, Wójtowicz T, Wójcicka O, Jaśkiewicz M, Drulis-Fajdasz D, et al. Targeting GSK3 signaling as a potential therapy of neurodegenerative diseases and aging. Expert Opin Ther Targets. 2018;22(10):833-48.

99. De Gasperi R, Sosa MAG, Dracheva S, Elder GA. Presenilin-1 regulates induction of hypoxia inducible factor-1a: altered activation by a mutation associated with familial Alzheimer's disease. Mol Neurodegener. 2010 Sep 23;5:38.

100. Zhang Z, Yan J, Chang Y, ShiDu Yan S, Shi H. Hypoxia inducible factor-1 as a target for neurodegenerative diseases. Curr Med Chem. 2011;18(28):4335-43.

101. Kim Y-S, Joh TH. Matrix metalloproteinases, new insights into the understanding of neurodegenerative disorders. Biomol Ther. 2012 Mar;20(2):133-43.

102. Brkic M, Balusu S, Libert C, Vandenbroucke RE. Friends or Foes: Matrix Metalloproteinases and Their Multifaceted Roles in Neurodegenerative Diseases. Mediators Inflamm. 2015;2015:620581.

103. Singh D, Srivastava SK, Chaudhuri TK, Upadhyay G. Multifaceted role of matrix metalloproteinases (MMPs). Front Mol Biosci. 2015;2:19.

104. Naphade S, Embusch A, Madushani KL, Ring KL, Ellerby LM. Altered Expression of Matrix Metalloproteinases and Their Endogenous Inhibitors in a Human Isogenic Stem Cell Model of Huntington's Disease. Front Neurosci. 2017;11:736.

105. Crary JF, Shao CY, Mirra SS, Hernandez Al, Sacktor TC. Atypical protein kinase C in neurodegenerative disease I: PKMzeta aggregates with limbic neurofibrillary tangles and AMPA receptors in Alzheimer disease. J Neuropathol Exp Neurol. 2006 Apr;65(4):319-26.

106. Lucke-Wold BP, Turner RC, Logsdon AF, Simpkins JW, Alkon DL, Smith KE, et al. Common mechanisms of Alzheimer's disease and ischemic stroke: the role of protein kinase $C$ in the progression of age-related neurodegeneration. J Alzheimers Dis JAD. 2015;43(3):711-24.

107. Kaleli HN, Ozer E, Kaya VO, Kutlu O. Protein Kinase C Isozymes and Autophagy during Neurodegenerative Disease Progression. Cells. 2020 Feb 27;9(3).

108. Chang JR, Ghafouri M, Mukerjee R, Bagashev A, Chabrashvili T, Sawaya BE. Role of p53 in neurodegenerative diseases. Neurodegener Dis. 2012;9(2):68-80.

109. Nakanishi A, Minami A, Kitagishi Y, Ogura Y, Matsuda S. BRCA1 and p53 tumor suppressor molecules in Alzheimer's disease. Int J Mol Sci. 2015 Jan 28;16(2):2879-92. 
110. Szybińska A, Leśniak W. P53 Dysfunction in Neurodegenerative Diseases - The Cause or Effect of Pathological Changes? Aging Dis. 2017 Jul;8(4):506-18.

111. Yuste JE, Tarragon E, Campuzano CM, Ros-Bernal F. Implications of glial nitric oxide in neurodegenerative diseases. Front Cell Neurosci. 2015;9:322.

112. Asiimwe N, Yeo SG, Kim M-S, Jung J, Jeong NY. Nitric Oxide: Exploring the Contextual Link with Alzheimer's Disease. Oxid Med Cell Longev. 2016;2016:7205747.

113. McCoy MK, Tansey MG. TNF signaling inhibition in the CNS: implications for normal brain function and neurodegenerative disease. J Neuroinflammation. 2008 Oct 17;5:45.

114. Frankola KA, Greig NH, Luo W, Tweedie D. Targeting TNF-a to elucidate and ameliorate neuroinflammation in neurodegenerative diseases. CNS Neurol Disord Drug Targets. 2011 May;10(3):391-403.

115. Jung YJ, Tweedie D, Scerba MT, Greig NH. Neuroinflammation as a Factor of Neurodegenerative Disease: Thalidomide Analogs as Treatments. Front Cell Dev Biol. 2019;7:313.

116. Maier $\mathrm{CM}$, Chan PH. Role of superoxide dismutases in oxidative damage and neurodegenerative disorders. Neuroscientist. 2002 Aug;8(4):323-34.

117. Pong K. Oxidative stress in neurodegenerative diseases: therapeutic implications for superoxide dismutase mimetics. Expert Opin Biol Ther. 2003 Feb;3(1):127-39.

118. Trist BG, Hare DJ, Double KL. A Proposed Mechanism for Neurodegeneration in Movement Disorders Characterized by Metal Dyshomeostasis and Oxidative Stress. Cell Chem Biol. 2018 Jul 19;25(7):807-816.

119. Hubálek F, Binda C, Khalil A, Li M, Mattevi A, Castagnoli N, et al. Demonstration of isoleucine 199 as a structural determinant for the selective inhibition of human monoamine oxidase $B$ by specific reversible inhibitors. J Biol Chem. 2005 Apr 22;280(16):15761-6.

120. Grodsky N, Li Y, Bouzida D, Love R, Jensen J, Nodes B, et al. Structure of the catalytic domain of human protein kinase $\mathrm{C}$ beta II complexed with a bisindolylmaleimide inhibitor. Biochemistry. 2006 Nov 28;45(47):13970-81.

121. Estébanez-Perpiñá E, Arnold LA, Arnold AA, Nguyen P, Rodrigues ED, Mar E, et al. A surface on the androgen receptor that allosterically regulates coactivator binding. Proc Natl Acad Sci U S A. 2007 Oct 9;104(41):16074-9.

122. Cheung J, Rudolph MJ, Burshteyn F, Cassidy MS, Gary EN, Love J, et al. Structures of human acetylcholinesterase in complex with pharmacologically important ligands. J Med Chem. 2012 Nov 26;55(22):10282-6.

123. Souza PCT, Textor LC, Melo DC, Nascimento AS, Skaf MS, Polikarpov I. An alternative conformation of ER $\beta$ bound to estradiol reveals H12 in a stable antagonist position. Sci Rep. 2017 Jun 14;7(1):3509.

\section{Figures}



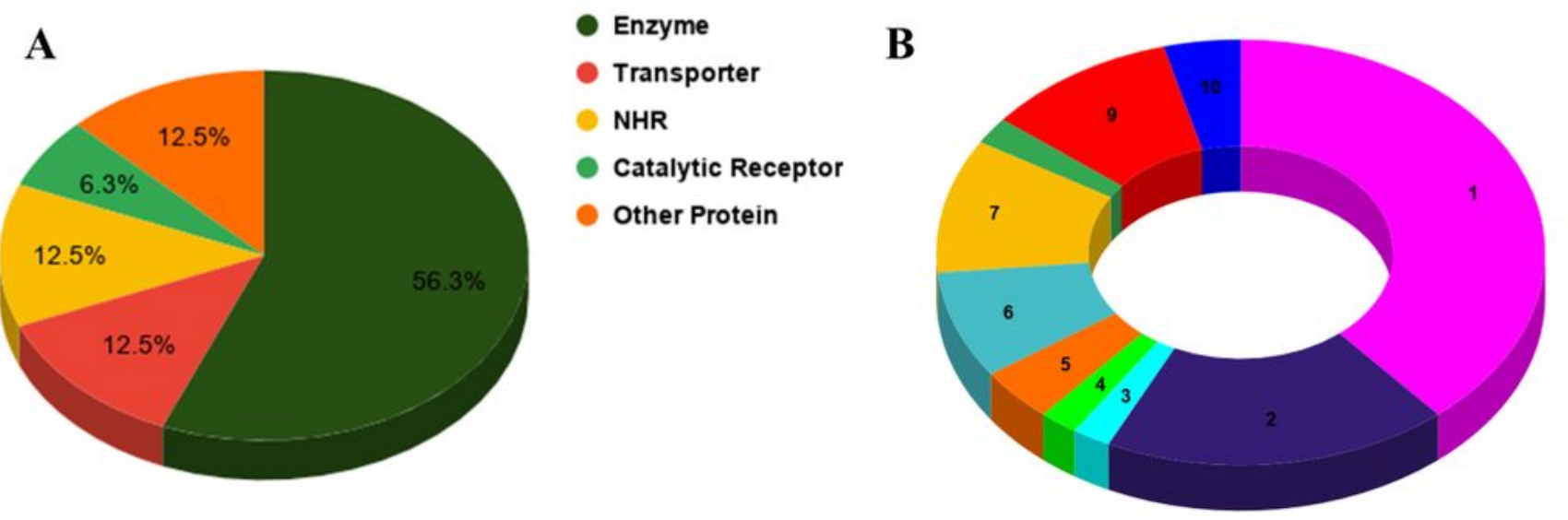

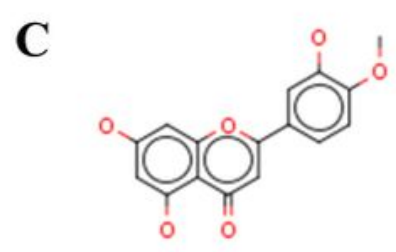

diosmetin<smiles>OCc1ccccc1O[C@@H]1O[C@H](CO)[C@@H](O)C(O)[C@H]1O</smiles>

salicin

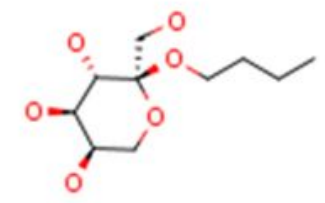

lobetyolin

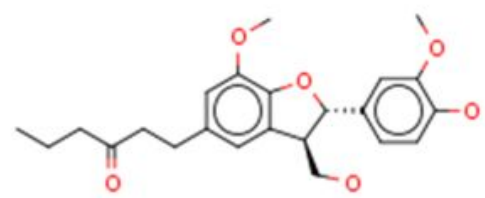

(-)(2R,3S)-2,3-dihydro-2-(4hydroxy-3-methoxy phenyl)-3hydroxy-methyl-7-methoxy-5benzofuran propanoic acid ethyl ester<smiles>Nc1ncnc2c1ncn2[C@@H]1O[C@H](CO)[C@@H](O)[C@H]1O</smiles>

$\mathrm{ADO}$

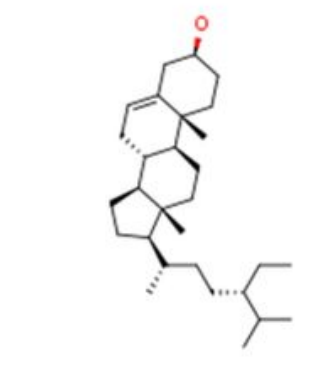

n-butyl- $\alpha$-D-fructopyranoside<smiles>O=C(O)CCC(=O)O</smiles>

succinic acid

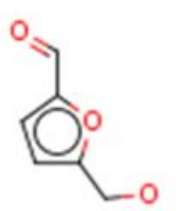

HMF 

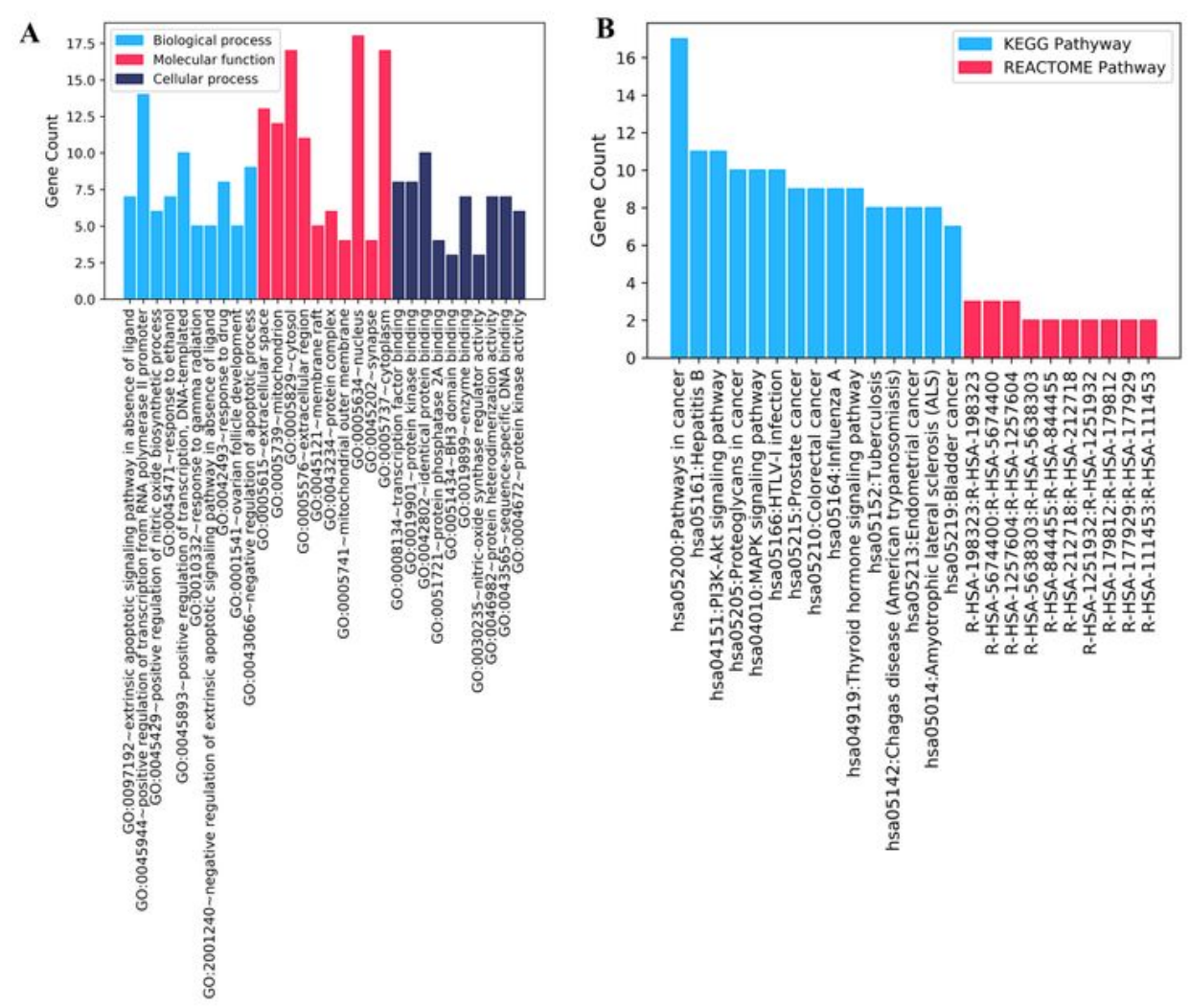

C

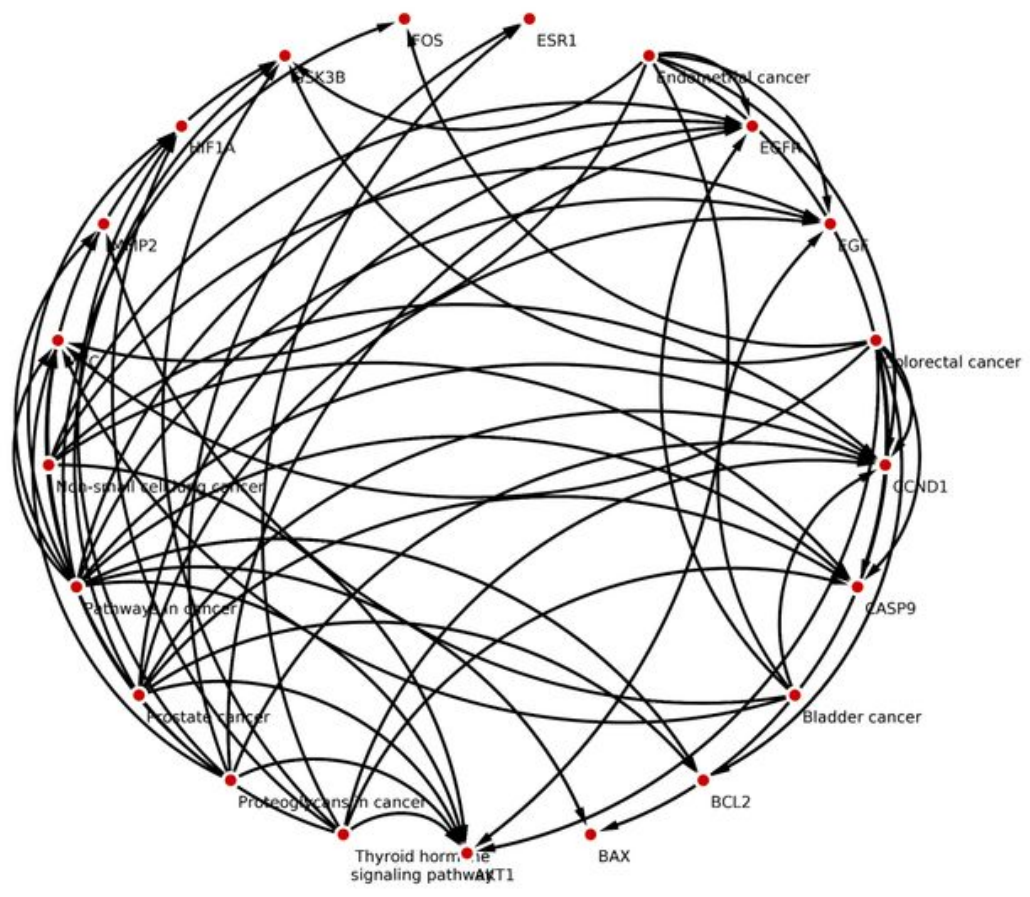

Figure 2

Gene Ontology (GO) term and signaling pathway enrichment analysis of the overlapped genes (Set II) related to the neuroprotective mechanism of the genus Lobelia. (A) GO analysis of the terms biological process, molecular function, and cellular component. (B) KEGG/ REACTOME pathways enrichment of the overlapped genes. (C) Key candidate pathways-targets interaction network. 

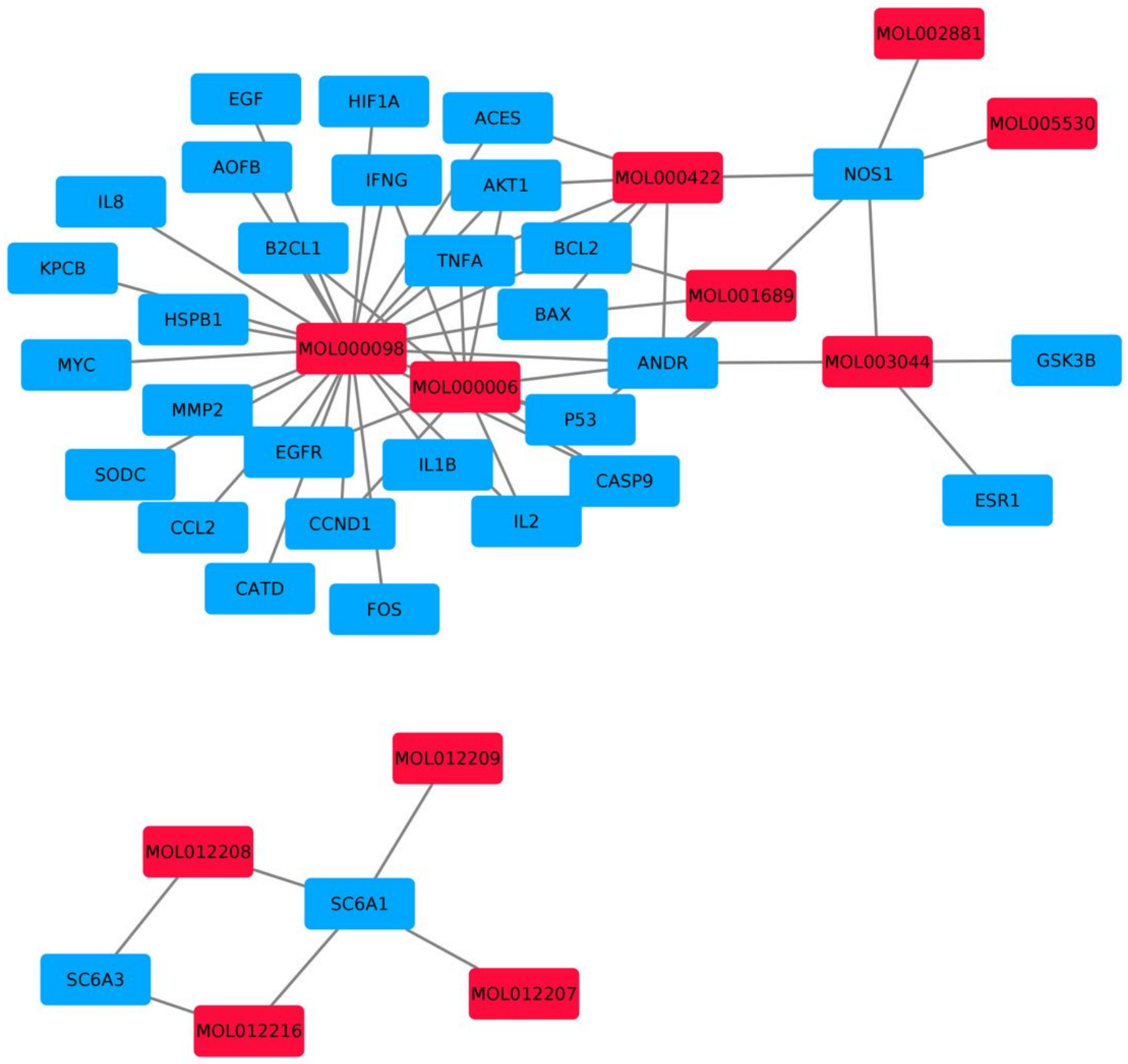

Figure 3

The compound-target network of the active ingredients of the genus Lobelia and the targets related to the neuroprotective mechanism. 


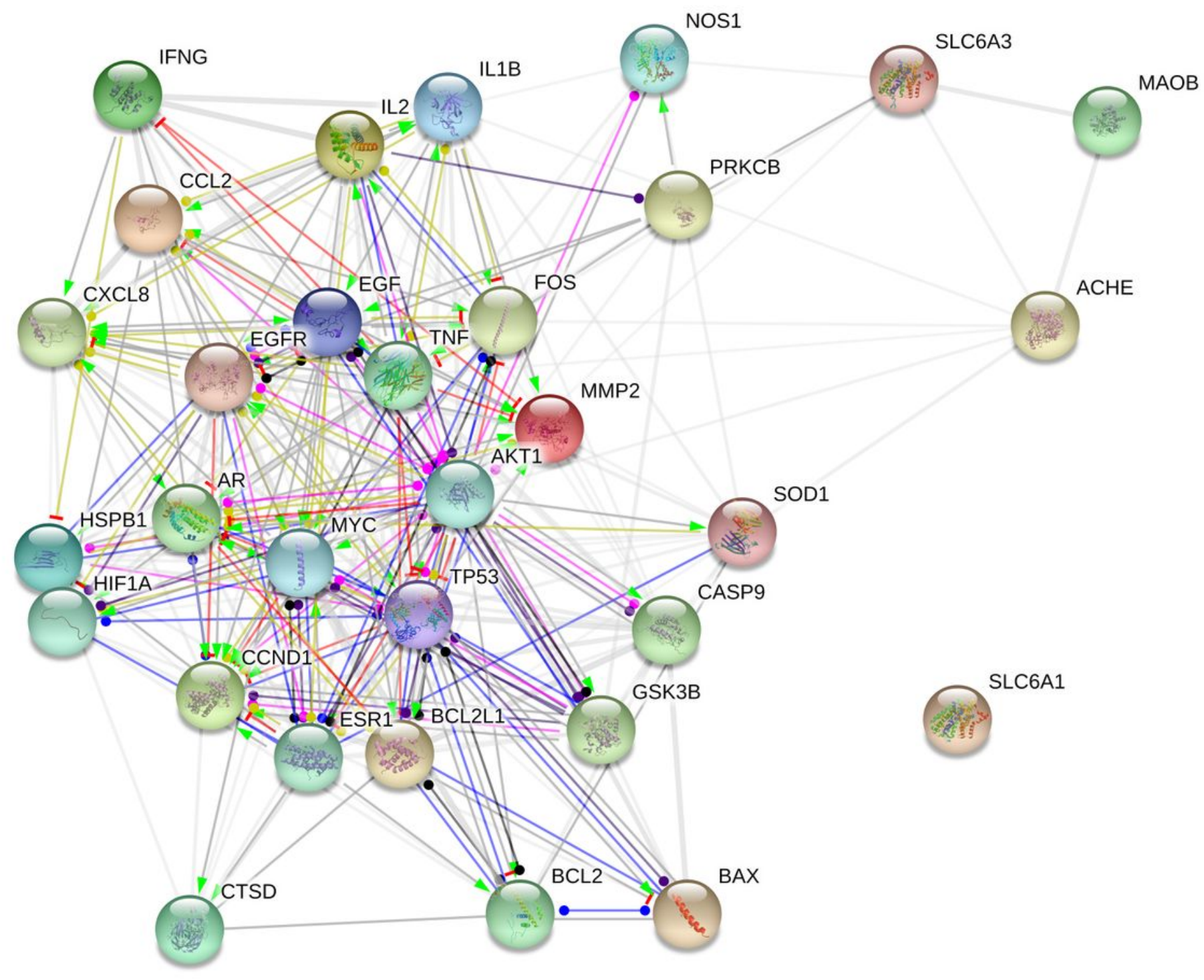

Figure 4

The PPI network of the neuroprotection associated candidate genes of the genus Lobelia. 

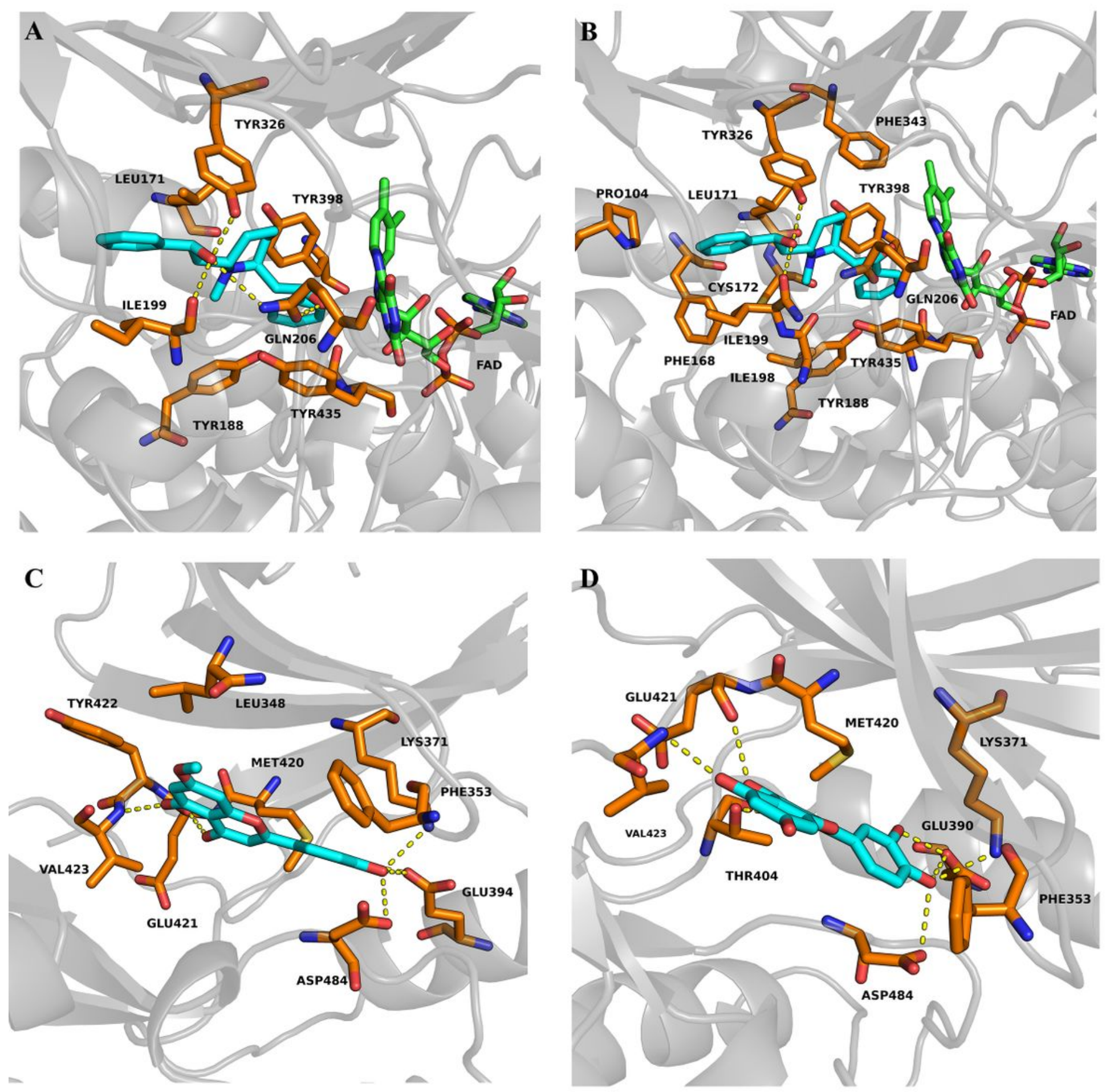

Figure 5

The binding pose of the selected ligands. A) Lobelanidine docked into the binding cavity of the protein MAOB; B) 2-[(2R,6S)-6-[(2R)-2-hydroxy-2-phenylethyl]-1-methylpiperidin-2-yl]-1-phenylethanone docked into the binding cavity of the protein $\mathrm{MAOB} ; \mathrm{C}$ ) Hydroxygenkwanin docked into the binding cavity of the protein PRKCB; D) Quercetin docked into the binding cavity of the protein PRKCB. The ligand is shown in cyan color and sticks representation. The active site residues are shown as orange sticks. The main 
atoms involved hydrogen bonds are indicated as yellow dashes. The key residues participating in hydrogen bonds and hydrophobic interactions are labeled.
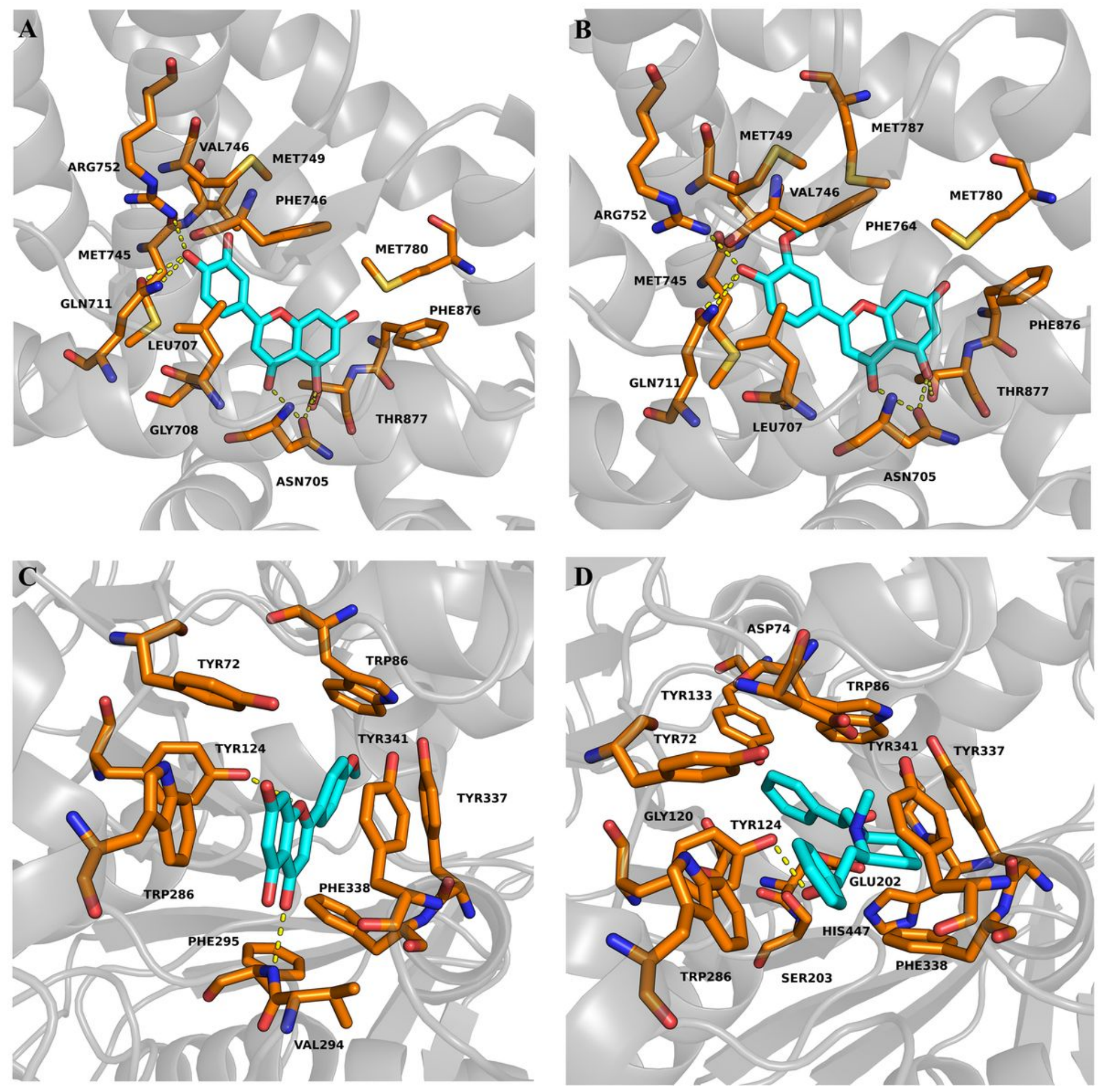

Figure 6

The binding pose of the selected ligands. A) Luteolin docked into the binding cavity of the protein ANDR; B) Chryseriol docked into the binding cavity of the protein ANDR; C) 2-[(2R,6S)-6-[(2R)-2-hydroxy-2phenylethyl]-1-methylpiperidin-2-yl]-1-phenylethanone docked into the binding cavity of the protein AChE; D) Lobelanidine docked into the binding cavity of the protein AChE. The ligand is shown in cyan color and sticks representation. The active site residues are shown as orange sticks. The main atoms involved 
hydrogen bonds are indicated as yellow dashes. The key residues participating in hydrogen bonds and hydrophobic interactions are labeled.
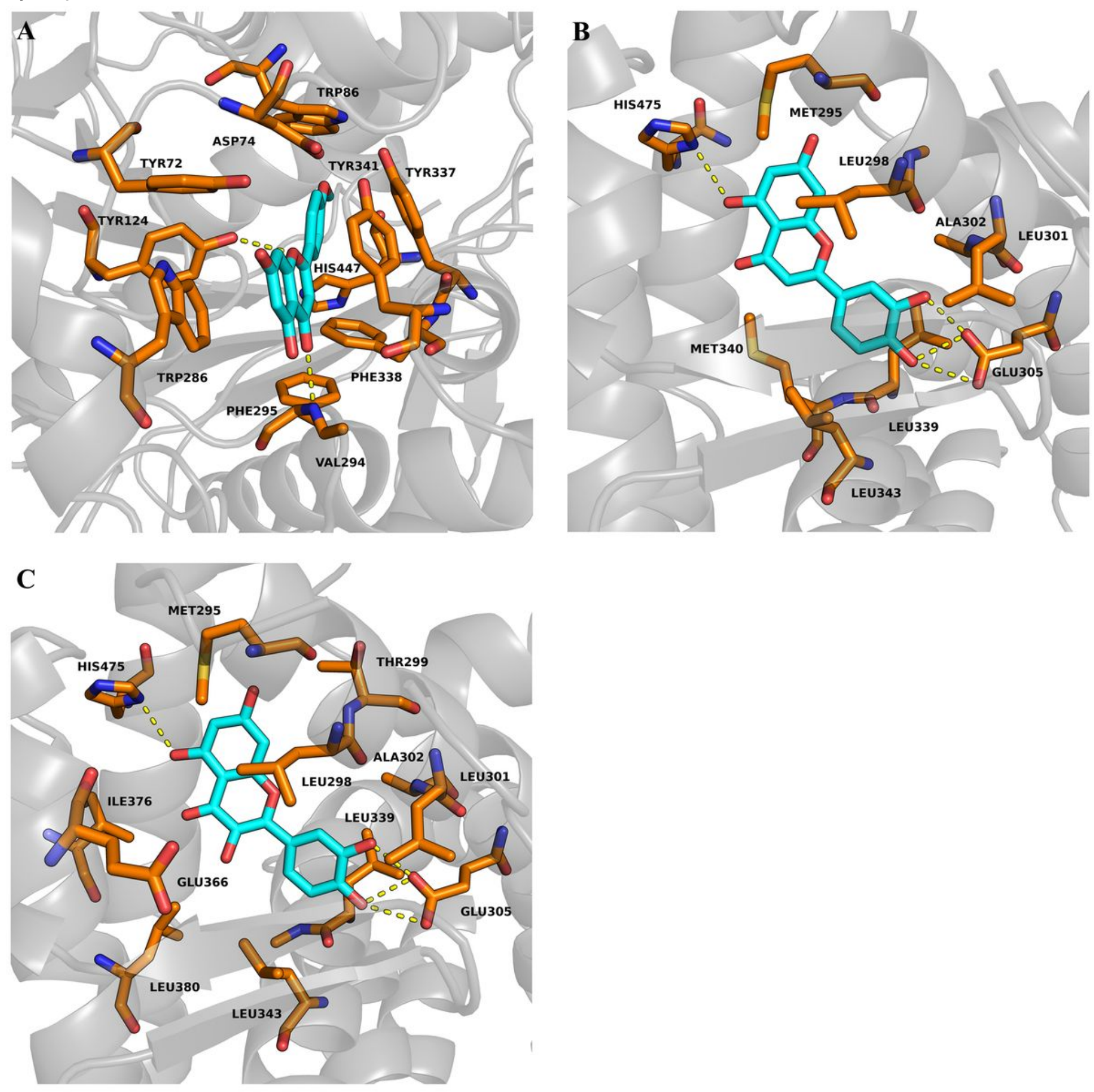

Figure 7

The binding pose of the selected ligands. A) Acacetin docked into the binding cavity of the protein AChE; B) Luteolin docked into the binding cavity of the protein ERB; C) Quercetin docked into the binding cavity of the protein ERß. The ligand is shown in cyan color and sticks representation. The active site residues 
are shown as orange sticks. The main atoms involved hydrogen bonds are indicated as yellow dashes. The key residues participating in hydrogen bonds and hydrophobic interactions are labeled.

\section{Supplementary Files}

This is a list of supplementary files associated with this preprint. Click to download.

- ChineseMedicineSupplementarylobelia.pdf 